\title{
Effect of Microwave Calcinations on Barium Hexaferrite Synthesized via Sol-Gel Combustion
}

\author{
S. Kanagesan ${ }^{a *}$, S. Jesurani ${ }^{a, b}$, M. Sivakumar ${ }^{a}$, C. Thirupathi ${ }^{a}$, and T. Kalaivani ${ }^{a}$ \\ ${ }^{\mathrm{a}}$ Center for Material Science and Nano Devices, Department of Physics, SRM University, \\ Kattankulathur-603 203, Tamil Nadu, India \\ ${ }^{b}$ Department of Physics, Jeyaraj Annapackium College for Women, Periyakulam-625601, \\ Tamil Nadu, India
}

Received 22 November 2010, accepted in revised form 26 July 2011

\begin{abstract}
In the present work we have shown a novel Barium hexaferrite $\left(\mathrm{BaFe}_{12} \mathrm{O}_{19}-\mathrm{BaF}\right)$ powder synthesized by a sol-gel combustion route using metal nitrates and D-Fructose. $\mathrm{BaFe}_{12} \mathrm{O}_{19}$ precursor was calcined using microwave furnace at $900^{\circ} \mathrm{C}$ for 10 minutes. The products were characterized by X-ray diffraction (XRD), high resolution scanning electron microscope (HR-SEM), and vibrating sample magnetometer (VSM), whose results indicate that they have well crystalline phase of barium hexaferrite, the diameter of the hexagonal platelet-like structure ranges from 50 to $100 \mathrm{~nm}$. Magnetic measurements showed that the coercivity was $5558.6 \mathrm{Oe}$ and saturation magnetization was $55.20 \mathrm{emu} / \mathrm{g}$. Magnetic measurements for the barium hexaferrite showed enhanced coercivity.
\end{abstract}

Keywords: Sol-gel combustion; Hexaferrite; D-Fructose; Remanent magnetization; Precursor.

(C) 2011 JSR Publications. ISSN: 2070-0237 (Print); 2070-0245 (Online). All rights reserved. doi:10.3329/jsr.v3i3.6483

J. Sci. Res. 3 (3), 451-456 (2011)

\section{Introduction}

Barium hexaferrite with hexagonal crystal structure has received much attention due to its excellent chemical and physical properties such as large magneto crystalline anisotropy, high Curie temperature, relatively large saturation magnetization, high coercive force, chemically inert, mechanically resilient and corrosion resistivity. For the most recording media, high saturation magnetization, high structural and low costs are important criteria. In the case of recording media such as hard disks, floppy disks and video tapes [1]. The mixed oxide ceramic method for preparing of barium hexaferrite requires a high calcining

${ }^{*}$ Corresponding author: kanagu1980@gmail.com 
temperature $\left(1200{ }^{\circ} \mathrm{C}\right.$ ), which induces aggregation on the particles. But the homogeneity is very less. An intrinsic property, such as saturation magnetization, is determined by material composition, where as an extrinsic property, such as magnetic coercivity is to a large extent, determined by the microstructure which is in turn influenced strongly by the processing procedures. For a magnetically optimized crystallite, a grain size of less than $1 \mu \mathrm{m}$ is required, with $80 \%$ of the theoretical maximum coercivity being reported for grains of $0.1 \mu \mathrm{m}$ [2]. In addition the microstructure is dependent on the particle size, homogeneity of the precursor material and sintering conditions [3]. The sol-gel technique provides a means for the atomic scale mixing of multiple components at low temperatures, resulting in a more homogenous precursor. Consequently improved sintering rates at lower temperatures can be expected, leading to improved microstructure. Various methods were used to prepare hexagonal ferrite powders in order to improve the magnetic properties, co precipitation [4], hydrothermal or microwave hydrothermal synthesis [5, 6], ammonium nitrate melt technique [7], sugar-nitrates process [8] and microwave-induced combustion process [9]. There is growing interest in the application of microwave heating to ceramics and metals [10-12]. Microwave heating is a very sensitive function of the material being processed and depends on several factors, such as sample size, density, mass and geometry [13]. Recently sintering of ceramics using microwave energy received much attention due to its many attractive features over conventional sintering. These include rapid volumetric controlled heating, high production rates and low energy consumption $[14,15]$, lower sintering temperature, reduced sintering time, environment friendly and capabilities of producing unique microstructure [16-18]. In literature, only few researchers reported the syntheses of hexaferrites using microwave calcination. In this paper, we report the synthesis and magnetic properties of barium hexaferrite by sol-gel combustion method using microwave calcination.

\section{Experimental}

In a typical synthesis of $\mathrm{BaFe}_{12} \mathrm{O}_{19}$ particles, ferric nitrate $\left[\mathrm{Fe}\left(\mathrm{NO}_{3}\right)_{3} 9 \mathrm{H}_{2} \mathrm{O}\right.$ ], barium nitrate $\left[\mathrm{Ba}\left(\mathrm{NO}_{3}\right)_{2}\right]$ and $\mathrm{D}$-fructose, were used as starting materials. We previously reported that a single phase barium hexaferrite material had been synthesized by the sol-gel combustion method [18]. The obtained precursor was calcination at $900^{\circ} \mathrm{C}$ for 10 minutes using microwave furnace. The phase formation of microwave calcined powders were identified from the characteristic diffraction peaks observed by X-ray analysis using (PANalytical X'pert pro), using CuK $\alpha$ radiation at $45 \mathrm{kV}$ and $40 \mathrm{~A}(\lambda=0.15406 \mathrm{~nm})$ in a wide range of $2 \theta\left(10^{\circ}<2 \theta<80^{\circ}\right)$. The crystalline powder was dispersed in acetone and coated on silicon wafer. The dispersed particles morphology was analyzed using FEI Quanta FEG 200 - high resolution scanning electron microscope (HR-SEM). The magnetic properties (coercivity, saturation, and remanent magnetization) were measured using a vibrating sample magnetometer (VSM, Lake Shore7304). 


\section{Results and Discussion}

The precursor was calcined at $900^{\circ} \mathrm{C}$ [19]. The XRD pattern of $\mathrm{BaF}$ powder (Fig. 1) exhibit typical peaks that can be indexed to the standard pattern of M-type $\mathrm{BaFe}_{12} \mathrm{O}_{19}$ crystals (JCPDS 39-1433). The broadening of the XRD peaks in the above samples indicates that the particles are sub-micron in size.

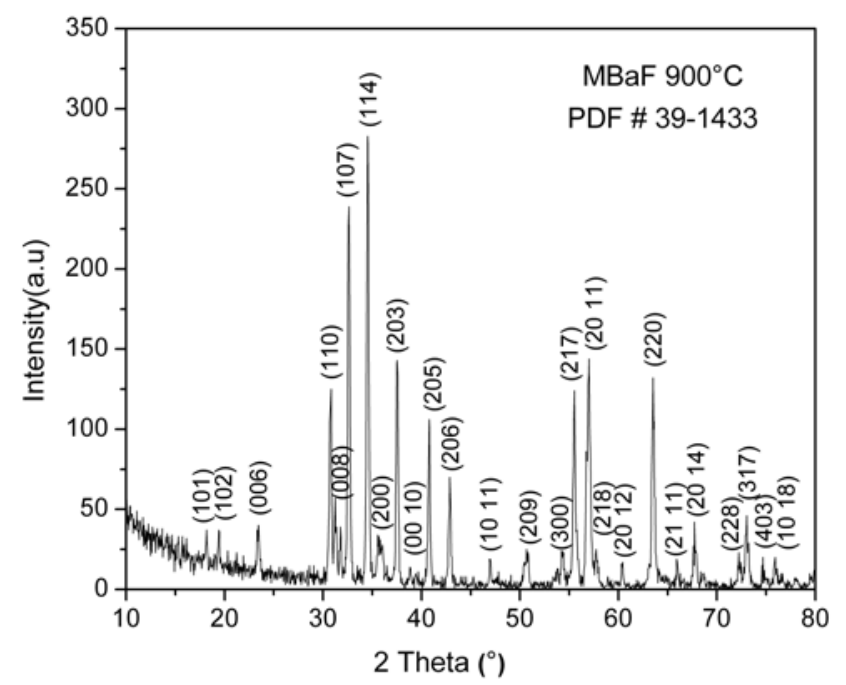

Fig. 1. X-Ray Diffraction patterns of calcined $\mathrm{BaFe}_{12} \mathrm{O}_{19}$ powders prepared by sol-gel combustion method.

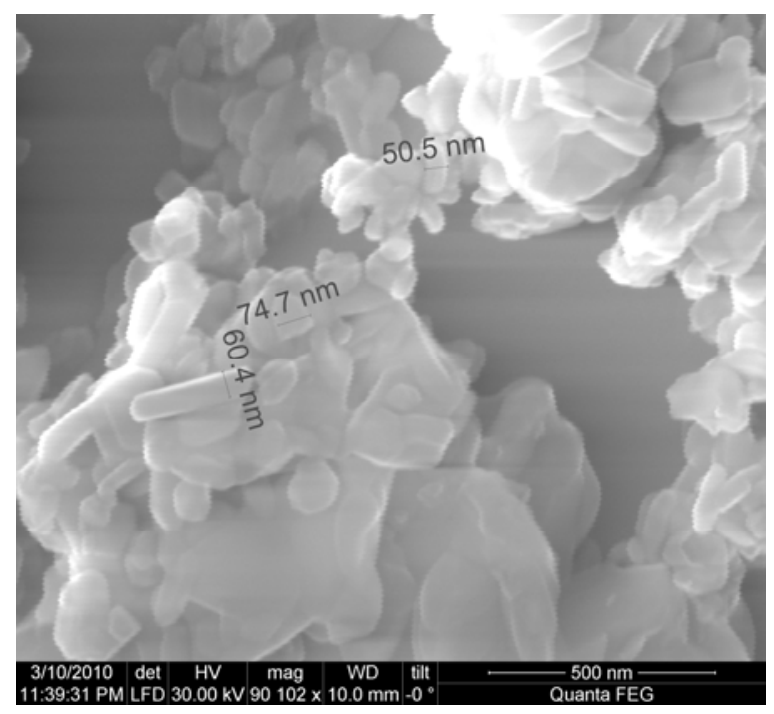

Fig. 2. HR-SEM Image of microwave calcined $\mathrm{BaF}$ at $900^{\circ} \mathrm{C}$ for 10 minutes. 
The shape of the particles was studied by HR-SEM micrograph for the calcined powder as shown in Fig. 2. Grains were irregular and well crystallized in hexagonal plate like shape, and measurement of few particles size was 50-100 nm. Probably, the irregular shape of the particles is due to the rapid simultaneous nucleation in the uniform temperature field and the secondary crystal growth with respect to the very short combustion process $[20,21]$.

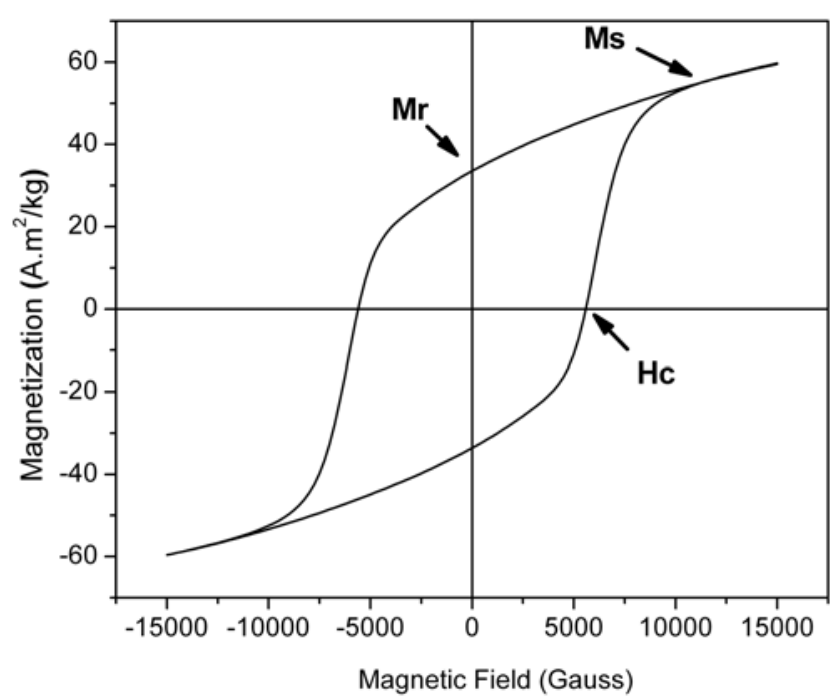

Fig. 3. Magnetization curve of $\mathrm{BaFe}_{12} \mathrm{O}_{19}$ powder calcined at $900{ }^{\circ} \mathrm{C}$ for 10 minutes.

Fig. 3 shows the saturation magnetization of $\mathrm{BaF}(55.20 \mathrm{emu} / \mathrm{g})$ is too far away from the theoretically estimated value of $72 \mathrm{emu} / \mathrm{g}$ [22] and the corecivity $\left(\mathrm{H}_{\mathrm{c}}\right)$ are found to be 5558.6 Oe, respectively. It is well known that the coercivity of barium ferrite depends on many factors, such as chemical composition, particle size, degree of crystallinity, microstructure, magnetic anisotropy, etc. However, recent progress indicate that the coercivity is also strongly influenced by the particle size [23-27], whose variation can also induce the obvious change in saturation magnetization and magnetic anisotropy, etc.

\section{Conclusion}

Microwave calcined hexagonal barium hexaferrite have been synthesized by the sol-gel combustion method using a metal nitrates in the presence of D-fructose. The obtained products exhibit well crystalline phase of $\mathrm{BaFe}_{12} \mathrm{O}_{19}$, typical platelet-like structure. The magnetic measurement for the microwave calcined barium hexaferrite was observed and the values are compared with previous research reports. The microwave calcined powder of $\mathrm{BaFe}_{12} \mathrm{O}_{19}$ exhibits enhanced hard magnetic property due to the reduced particle size. 


\section{Acknowledgements}

The authors thank SRM University for providing the facilities available in Nanotechnology Centre.

\section{References}

1. X. Liu, J. Wang, L. M. Gan, and S. C. Ng, Magn. Magn. Mater. 195, 452 (1999). doi:10.1016/S0304-8853(99)00123-7

2. K. Haneda and H. Kojima, J. Appl. Phys. 44, 3760 (1973). doi:10.1063/1.1662836

3. R. L. Coble, J. Appl. Phys 32, 787 (1961). doi:10.1063/1.1736107

4. D. Lisjak and M. Drofenik, J. Mater. Sci 42, 8606 (2007). doi:10.1007/s10853-007-1850-0

5. M. Drofenik, M. Kristl, A. Znidarsic, D. Hanzel and D. Lisjak, J. Am. Ceram. Soc. 90, 2057 (2007). doi:10.1111/j.1551-2916.2007.01740.x

6. T. Yamauchi, Y. Tsukahara, T. Sakata, H. Mori, T. Chikata, S. Katoh and Y. Wada, J. Magn. Magn. Mater. 321, 8 (2009). doi:10.1016/j.jmmm.2008.07.005

7. U. Topal, H. Ozkan and K. G. Topal, J. Alloys. Compd. 422, 276 (2006). doi:10.1016/j.jallcom.2005.11.043

8. X. Tang, B. Y. Zhao and K. A. Hu, J. Mater. Sci. 41, 3867 (2006). doi:10.1007/s10853-006-6676-7

9. Y-p. Fu, C-H. Lin and K-Y. Pan, J. Alloys. Compd. 364, 221(2004). doi:10.1016/S0925-8388(03)00501-2

10. D. E. Clark and W. Sutton, Ann. Rev. Mater. Sci. 26, 299 (1996). doi:10.1146/annurev.ms.26.080196.001503

11. K. H. Brosnan, G. L. Messing and D. K. Agrawal, J. Am. Ceram. Soc. 86, 1307 (2003). doi:10.1111/j.1151-2916.2003.tb03467.x

12. M. Panneerselvam and K. J. Rao, Mater. Res. Bull. 38, 663 (2003). doi:10.1016/S0025-5408(02)01071-1

13. R. M. Hutcheon, M. S. De Jong and F. P. Adams, Ceram. Trans. Am. Ceram. Soc. 59, 215 (1995).

14. Y. Fang, R. Roy, D. K. Agrawal and D. M. Roy, Mater. Lett. 28, 11 (1996). doi:10.1016/0167-577X(96)00028-6

15. P. Piluso, L. Gaillard, N. Lequeux and P. Boch, J. Eur. Ceram. Soc. 16, 121(1996). doi:10.1016/0955-2219(95)00134-4

16. S. Chockalingam, D. A. Earl and V. W. Amarakoon, Int. J. Appl. Ceram. Technol. 6, 102 (2009). doi:10.1111/j.1744-7402.2008.02259.x

17. S. Chockalingam and V. R. W. Amarakoon, J. Ceram. Soc. Jpn. 116, 700 (2008). doi: $10.2109 /$ jeersj 2.116 .700

18. S. Chockalingam, J. George, D. A. Earl, and V. R. W. Amarakoon, J. Microw. Power. Electromagn. Energy 42, 4 (2008).

19. S. Kanagesan, S. Jesurani, R. Velmurugan and C. Kumar, J. Manufact. Eng. 5, 133 (2010).

20. L. Junliang, Z. Yanwei, G. Cuijing, Z. Wei and Y. Xiaoweib, J. Eur. Ceram. Soc. 30, 993 (2010). doi:10.1016/j.jeurceramsoc.2009.10.019

21. S. Castro, M. Gayoso and C. Rodringuez, J. Solid. State. Chem. 134, 227 (1997). doi:10.1006/jssc. 1997.7523

22. K. Haneda and H. Kojima, J. Appl. Phys 44, 3760 (1973). doi:10.1063/1.1662836

23. J. Dho, E. K. Lee, J. Y. Park and N. H. Hur, J. Magn. Magn. Mater 285,164 (2005). doi:10.1016/j.jmmm.2004.07.033

24. Y. F. Lu and W. D. Song, Appl. Phys. Lett. 76, 490 (2000). doi:10.1063/1.125797

25. P. Ren, J. G. Guan and X. D. Cheng, Mater. Chem. Phys. 98, 90 (2006). doi:10.1016/j.matchemphys.2005.08.070 


\section{Effect of Microwave Calcinations}

26. G. Mendoza-Suarez, J. A. Matutes-Aquino, J. I. Escalante-Garcia, H. Mancha-Molinar, D. Rios- Jara and K. K. Johal, J. Magn. Magn. Mater. 223, 55 (2001).

27. S. R. Janasi, M. Emura, F. J. G. Landgraf and D. Rodrigues, J. Magn. Magn. Mater. 238, 168 (2002). doi:10.1016/S0304-8853(01)00857-5 